\title{
Syntactic Dependencies and Verbal Inflection: Complementisers and Verbal Forms in Standard Arabic
}

\author{
Feras Saeed \\ Unaizah Community College, Qassim University, Kingdom of Saudi Arabia, \\ E-mail: ferasaeed@yahoo.com
}

Doi:10.7575/aiac.alls.v.6n.6p.131

URL: http://dx.doi.org/10.7575/aiac.alls.v.6n.6p.131
Received: 09/07/2015

Accepted: 15/09/2015

\begin{abstract}
This paper investigates the syntactic dependency between complementisers and verbal forms in Standard Arabic and provides a new analysis of this dependency. The imperfective verb in this language surfaces with three different forms, where each form is indicated by a different suffixal marker attached to the end of the verb as $(-u),(-a)$, or $(-\varnothing)$. The occurrence of each suffixal marker on the verb corresponds to the co-occurrence of a particular type of Comp-elements in the $\mathrm{C} / \mathrm{T}$ domain. I argue that these morphological markers on the three verbal forms are the manifestation of an Agree relation between an interpretable unvalued finiteness feature [Fin] on $\mathrm{C}$ and an uninterpretable but valued instance of the same feature on v, assuming feature transfer and feature sharing between C/T and v (Pesetsky \& Torrego 2007; Chomsky 2008). I also argue that the different verbal forms in Standard Arabic are dictated by the co-occurrence of three types of Comp-elements: i) C-elements; ii) T-elements which ultimately move to C; and iii) imperative/negative elements.
\end{abstract}

Keywords: feature transfer/sharing, verbal forms, complementisers, finiteness, syntactic dependency, Standard Arabic

\section{Introduction}

The verb in Standard Arabic inflects for several categories; and in some cases a single morpheme encodes information of more than one category. Broadly speaking, the verb in Standard Arabic has three major paradigms: i) the imperative, ii) the perfective, and iii) the imperfective.

The imperative verb is associated with commands and orders and usually has two forms: i) the positive form, and ii) the negative form. The positive/negative distinction on the imperative verb is manifested in the form of two different prefixal markers, whereas suffixal inflection on the imperative verb stands for subject-verb agreement.

The perfective verb is associated with past tense temporal interpretation and can only have suffixal inflection. While verb-endings in the perfective form stand for subject-verb agreement, tense/aspect is usually expressed via certain vocalic changes to the verb stem.

The imperfective verb is associated with present, future, or non-finite temporal interpretation, and can have prefixal as well as suffixal inflection. While prefixal inflection on the imperfective verb usually stands for subject-verb agreement, the morpho-syntactic nature of suffixal inflection on this verb is still an unsolved puzzle. The imperfective verb surfaces with three different suffixal markers attached to the end of the verb as $(-u),(-a)$, or $(-\varnothing)$. These three verbal forms have been traditionally dubbed by Arab grammarians: the indicative form, the subjunctive form, and the jussive form. These three labels are merely cover terms and do not necessarily represent real mood. Understanding the nature of these suffixal morphological markers on the three verbal forms of the imperfective verb in Standard Arabic and what they stand for constitute the core part of the syntactic investigation in this paper.

It is important to point out that while the imperative and perfective verbs tend to preserve the same morphological marker without alternation, be it a prefix or a suffix, irrespective of the syntactic context in which these verbs occur (AlBalushi 2011), the morphological marker on the imperfective verb, especially the suffixal marker, varies according to the syntactic context in which the verb occurs. Therefore, this paper will investigate the different syntactic contexts that correspond to the occurrence of the three different morphological forms of the imperfective verb in Standard Arabic.

This paper is divided as follows: in the second section, I discuss the main characteristics of the three imperfective verbal forms in Standard Arabic. In the third section, I evaluate the three major approaches in the literature that have tried to account for the three different morphological markers on the imperfective verb. In the fourth section, I provide a new analysis of verbal forms in Standard Arabic based on the notion of feature transfer/sharing (Pesetsky \& Torrego 2007; Chomsky 2008). In the fifth section, I examine the syntactic context of two types of Comp-elements in Standard Arabic. The last section summarizes the main findings and arguments of this study.

\section{Verbal Forms in Standard Arabic}

Verb-endings on the imperfective verb in standard Arabic create an inexplicable type of inflection which is realized on three verbal forms, traditionally known as the indicative, the subjunctive, and the jussive. These verbal forms occur in 
tensed and non-tensed contexts as well as main and embedded clauses. Each verbal form is characterized by the cooccurrence of particular Comp-elements which seem to dictate the type of morphological marker on the verb. In the following sub-sections, I discuss the characteristics of each of these verbal forms.

\subsection{The Indicative Form}

The indicative form of the verb in Standard Arabic is usually realized by the suffixal marker $-u^{1}$ :

1) yaktub-u resaalat-an kullayaum

3m.write-ind letter-acc everyday

'He writes a letter everyday'

2) taktub-u resaalat-an kullayaum

3f.write-ind letter-acc everyday

'She writes a letter everyday'

This verbal form can occur after future modals/particles like $s a$ - and sawfa:

3) sa-tughadir-u ghadan

will-3f.leave-ind tomorrow

'She will leave tomorrow'

4) sawfa tughadir-u ghadan

will 3f.leave-ind tomorrow

'She will leave tomorrow'

It also occurs in interrogative sentences:

5) li-maatha takrah-u-hu

for-what 2.hate-ind-him

'Why do you hate him?'

6) maatha tureed-u min-hu

what 2.want-ind from-him

'What do you want from him?'

The indicative verbal form can also occur in passive structures:

7) tulaff-u bi-inaayatin houl ar-ragabah

3f.wrap-ind with-care around the neck

'It should be wrapped carefully around the neck'

8) yustaxdam-u li-zeenati

3 m.use-ind for-decoration

'It is used for decoration'

In addition, the indicative verbal form can occur in main clauses that are headed by the sentential complementiser inna:

9) inna-hu yanaam-u

katheeran

Comp-he $3 \mathrm{~m}$.sleep-ind a lot

'(Indeed), he sleeps a lot'

It can also occur in embedded clauses that are headed by the subordinating complementiser anna:

10) adhun-u anna-ha tanaam-u katheeran

1.think-ind Comp-she 3f.sleep-ind a lot

'I think that she sleeps a lot'

However, the indicative verbal form cannot occur in embedded clauses that are headed by certain Comp-elements such as an, kay, li, likay:

11) *yureed-u an yaktub-u resaalat-an

$3 \mathrm{~m}$.want-ind to $3 \mathrm{~m}$.write-ind letter-acc

'He wants to write a letter'

12) *igraa kay tafham-u

2.read in-order-to 2.understand-ind

'Read in order to understand'

13) *nagraa-u li-nataalam-u

1.read-ind for-1.learn-ind

'We read to learn'

14) *izraa likay tahsud-u

2.sow in-order-to 2.reap-ind

'Sow in order to reap'

Nor can it occur after negative auxiliaries such as lan and lam:

\footnotetext{
${ }^{1}$ For expository purposes, the three morphological markers under study will be glossed as: $-u$ ind, $-a$ sub, and $-\varnothing$ jus. The gloss of these markers is merely indicative, to keep up with the traditional description, and does not represent real mood.
} 
won't 3f.write-ind letter-acc

'She will not write a letter'

16) *lam yaktub-u resaalat-an

didn't 3m.write-ind letter-acc

'He did not write a letter'

Table 1. The full paradigm of the indicative forms.

\begin{tabular}{rrrr}
\hline First person & Singular & Dual & Plural \\
\hline Second+masculine & $\begin{array}{r}\text { aa-ktub-u } \\
\text { 1-write-ind }\end{array}$ & $\begin{array}{r}\text { na-ktub-u } \\
1-\text { write-ind }\end{array}$ & $\begin{array}{r}\text { na-ktub-u } \\
1-\text { write-ind }\end{array}$ \\
\hline Second+feminine & ta-ktub-u & ta-ktub-aa-n & ta-ktub-uu-n \\
\hline Third+masculine & ta-ktub-ii-n & ta-ktub-aa-n & ta-ktub-n-a \\
\hline Third+feminine & ya-ktub-u & ya-ktub-aa-n & ya-ktub-uu-n \\
\hline & ta-ktub-u & ta-ktub-aa-n & ya-ktub-n-a \\
\hline
\end{tabular}

\subsection{The Subjunctive Form}

The subjunctive form of the verb in Standard Arabic occurs mainly in embedded clauses that are headed by the Compelement $a n$. The subjunctive verbal form is realized by the suffixal marker $-a$ :

17) yureed-u an yanaam-a

$3 \mathrm{~m}$.want-ind to $3 \mathrm{~m}$.sleep-sub

'He wants to sleep'

18) tureed-u an tanaam-a

3f.want-ind to 3f.sleep-sub

'She wants to sleep'

The subjunctive form of the verb occurs when preceded by certain Comp-elements such as kay, li, likay and hatta:

19) yadrus-u kay yanjah-a fi l-emtihani

$3 \mathrm{~m}$.study-ind so-that $3 \mathrm{~m}$.pass-sub in the-exam

'He studies to pass the exam'

20) yaeesh-u li-yakul-a

$3 \mathrm{~m}$. live-ind in-order-to-3m.eat-sub

'He lives to eat'

21) tukafeh-u likay taeesh-a

3f.struggle-ind in-order-to 3f.live-sub

'She struggles in order to live'

22) yadrus-u hatta yanjah-a fi l-emtihan

$3 \mathrm{~m}$.study-ind in-order-to $3 \mathrm{~m}$.pass-sub in the-exam

'He studies in order to pass the exam'

Another distinct characteristic of the subjunctive verbal form is that, unlike the indicative form, it can actually occur after the negative auxiliary lan:

23) lan tathhab-a ila s-soog-i

won't 3f.go-sub to the-market-gen

'She will not go to the market'

The subjunctive form of the verb occurs, also, when the clause is headed by negative Comp-elements such as kay-la, likay-la, and hatta-la (Ryding 2005: 610-611):

24) kay-la yabga-a gawiyyan

so-that-not 3m.remain-sub strong

'So that, it does not remain strong'

25) likay-la tadxul-a 1-maktab-a

in-order-that-not 3 f.enter-sub the-office-acc

'In order that she does not enter the office'

26) hatta-la yasgut-a fi l-hufrat-i

so-that-not $3 \mathrm{~m}$.fall-sub in the-hole-gen

'So that, he does not fall in the hole/pit'

However, this verbal form cannot occur in main clauses, or after the complementiser inna:

27) *tanaam-a katheeran

3f.sleep-sub a lot

'She sleeps a lot' 


28) *inna Zayd-an yanaam-a katheeran

Comp Zayd-acc 3m.sleep-sub a lot

'(Indeed), Zayd sleeps a lot'

Nor can it occur in embedded clauses that are headed by the complementiser anna:

29) *aa-dhun-u anna Zayd-an yanaam-a katheeran

1s-think-ind Comp Zayd-acc 3m.sleep-sub a lot

'I think that Zayd sleeps a lot'

Table 2. The full paradigm of the subjunctive forms.

\begin{tabular}{|c|c|c|c|}
\hline & Singular & Dual & plural \\
\hline \multirow[t]{2}{*}{ First person } & aa-ktub-a & na-ktub-a & na-ktub-a \\
\hline & 1-write-sub & 1-write-sub & 1-write-sub \\
\hline Second + masculine & ta-ktub-a & ta-ktub-aa-Ø & ta-ktub-uu-Ø \\
\hline Second + feminine & ta-ktub-ii-Ø & ta-ktub-aa-Ø & ta-ktub-n-a \\
\hline Third+masculine & ya-ktub-a & ya-ktub-aa-Ø & ya-ktub-uu-Ø \\
\hline Third+feminine & ta-ktub-a & ta-ktub-aa-Ø & ya-ktub-n-a \\
\hline
\end{tabular}

\subsection{The Jussive Form}

The jussive verbal marker is phonologically null; and this verbal form usually occurs after certain negation particles such as lam, lamma and laa:

30) lam tanam- $\varnothing$ ilbaarehata

didn't 3f.sleep-jus last night

'She did not sleep last night'

31) lamma yathhab- $\varnothing$ baad

hasn't 3m.go-jus yet

'He has not gone yet'

32) laa tafgid- $\varnothing$ al-amal

not 2.lose-jus the-hope

'Do not lose hope'

In addition, the jussive verbal form is used in imperatives:

33) tamarran- $\varnothing$ kullayoum

2.exercise-jus everyday

'Exercise everyday'

Moreover, the jussive form occurs after some conditional particles such as in:

34) in tadrus- $\varnothing$ tajtaaz- $\varnothing$ al-imtihaan

if 2.study-jus 2.pass-jus the-exam

'If you study, you pass the exam'

Furthermore, this verbal form occurs after $w h$-adverbs:

35) mahma yahsul- $\varnothing$ laa tagif- $\varnothing$

whatever 3m.happen-jus not 2.stop-jus

'Whatever happens, do not stop'

36) aynama aathhab- $\varnothing$ aa-jed- $\varnothing$ sadeeg-an

wherever 1.go-jus 1.find-jus friend-acc

'Wherever I go, I find a friend'

Table 3. The full paradigm of the jussive forms.

\begin{tabular}{|c|c|c|c|}
\hline & singular & dual & Plural \\
\hline \multirow[t]{2}{*}{ First person } & aa-ktub-Ø & na-ktub-Ø & na-ktub-Ø \\
\hline & 1-write-jus & 1-write-jus & 1-write-jus \\
\hline Second+masculine & ta-ktub-Ø & ta-ktub-aa-Ø & ta-ktub-uu-Ø \\
\hline Second+feminine & ta-ktub-ii-Ø & ta-ktub-aa-Ø & ta-ktub-n-Ø \\
\hline Third+masculine & ya-ktub-Ø & ya-ktub-aa-Ø & ya-ktub-uu-Ø \\
\hline Third+feminine & ta-ktub-Ø & ta-ktub-aa-Ø & ya-ktub-n-Ø \\
\hline
\end{tabular}

\section{Literature Review}

There have been several attempts in the literature to account for these morphological markers that appear on the imperfective verb in Standard Arabic. However, all the previous accounts adopt one form or another of the following 
three approaches to these markers: i) these are tense markers, ii) case markers, or iii) mood markers. In the three subsections below, I briefly evaluate the main claims of three recent accounts of verbal morphology in Standard Arabic.

\subsection{Syntactic Dependency and Tense (Gallego, 2010)}

Gallego (2010) investigates the syntactic configuration of phases and proposes that head movement is an instance of phase extension or what he terms 'phase sliding'. He also examines null subject languages (NSLs) in order to investigate whether Chomsky's $(2007,2008)$ and Pesetsky and Torrego's $(2001,2007)$ systems can be used to account for their syntactic intricacies with regard to dependencies between $\mathrm{C} / \mathrm{T}$ and $\mathrm{v}$ in the $\mathrm{CP}$ phase. After pointing out the problems of adopting either Chomsky's analysis of assuming that the C/T-v dependency is based on agreement features, or Pesetsky and Torrego's analysis of contending that the C/T-v dependency arises because they all share the feature T, Gallego provides a new analysis that explains the dependency between $\mathrm{C} / \mathrm{T}$ and v. Gallego argues that C, T, and v can actually share one and the same feature, i.e., [Tense] which can surface in three values: past, present, and future. The reasoning he provides for choosing tense to be the feature that is shared by $\mathrm{C}, \mathrm{T}$, and $\mathrm{v}$, is that "[Tense] is a deictic formative that affects the clause as a whole." (Gallego 2010: 102). He reiterates that "The syntactic C-T-v dependency is established through [tense]" (Gallego 2010: 103). To demonstrate this dependency graphically, Gallego presents the following representation:

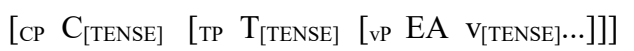

To account for verbal morphology and head movement in (NSLs), Gallego argues that the head C has an interpretable unvalued feature [Tense]. $\mathrm{C}$ acts as a probe to value its own [Tense] feature against an uninterpretable valued instance of [Tense] on $\mathrm{v}$. To avoid problems of intervention effects that might arise because of the head $\mathrm{T}$, the verb undergoes head movement to the left of $\mathrm{T}$ where the $\mathrm{C}$ probe can check its [Tense] feature against $\mathrm{v}$. Both $\mathrm{C}$ and $\mathrm{v}$ establish an Agree relation to value the [Tense] feature on $\mathrm{C}$. The benefits of this analysis, he argues, is that not only verbal morphology and its dependency on $\mathrm{C}$ can be explained, but also head movement in null subject languages receives a straightforward explanation. He terms verb movement to $\mathrm{T}$ as 'phase sliding', assuming that this obligatory movement of the verb in null subject languages actually slides or extends the boundary of the vP phase into TP.

Apparently, Gallego's (2010) proposal that tense is a feature on C which gets valued through matching or checking with the verb faces some theoretical as well as empirical challenges.

Theoretically, it has been argued that the head $\mathrm{T}$ actually carries a valued [Tense] feature, because it is $\mathrm{T}$ that encodes the tense interpretation of the clause (Biberauer \& Roberts 2010). If this is true, then Gallego's assumption that the head $\mathrm{C}$ probes $\mathrm{v}$ to value its [Tense] feature is untenable. Gallego's [Tense] feature seems to be a formal feature that needs checking via Agree, just like other formal features. This assumption, actually, does not seem to offer anything new to account for verbal morphology, apart from the new terminology of the same feature.

In addition, Gallego's assumption minimizes the role of the functional category TP and relegates it to a mere dummy element or a place holder of properties that belong to $\mathrm{C}$. Therefore, vacating the head $\mathrm{T}$ of all other features leaves us with a vacuous functional head in the syntactic skeleton which is parasitic on what is thrown out of $\mathrm{C}$; a situation that should call for the elimination of this dummy head which cannot be a phase head, nor a holder of any type of features.

Does tense truly belong to C, much like $\phi$-features? Chomsky (2007) sketches two possible answers to this question:

What is true of agreement features appears to hold as well for Tense: in clear cases, $\mathrm{T}$ has this feature if and only if selected by $\mathrm{C}$, though $\mathrm{C}$ never (to my knowledge) manifests Tense in the manner of $\phi$-features in some languages. If that is basically accurate, then there are two possibilities. One is that Tense is a property of $\mathrm{C}$, and is inherited by $\mathrm{T}$. The other is that Tense is a property of $\mathrm{T}$, but receives only some residual interpretation unless selected by $\mathrm{C}$ (or in other configurations, e.g., in English-like modal constructions). (Chomsky 2007: 20.)

In fact, Chomsky (2007) reports empirical and conceptual motivation in favor of the second option, noting that inheritance is not forced, since tense is interpretable.

Empirically, this account of featural dependency which is based on tense cannot explain the appearance of the same morphological marker on the verb in tensed and non-tensed contexts alike. For example, in simple declarative sentences the verb surfaces with the indicative marker $-u$ as a suffix:

38) yaktub-u resaalat-an kullayaum

$3 \mathrm{~m}$.write-ind letter-acc everyday

'He writes a letter everyday'

Similarly, in passive sentences, the non-tensed verb can also surface with the same indicative marker:

39) yustaxdam-u li-zeenati

3m.use-ind for-decoration

'It is used for decoration'

If Gallego's (2010) proposal is on the right track, the verb in passive sentences in Standard Arabic should not have this marker in this context, or at least it should have a different morphological marker that appears on non-tensed verbs. 
The other empirical problem with Gallego's account is that, though Standard Arabic is a null subject language and supposedly should comply with his analysis, this language does not have a specific morpheme or marker that indicates tense. The verb in this language inflects for aspect, not tense, that is why verb categories are divided into perfective and imperfective (Ryding 2005). Tense and aspect in Standard Arabic is expressed via certain vocalic changes to the verb stem:

40) The perfective verb kataba 'wrote': $k-a-t-a-b-(a)$

\section{$\mathrm{C}-\mathrm{V}-\mathrm{C}-\mathrm{V}-\mathrm{C}$}

The verb kataba above can be glossed as the past tense of the verb 'write'. The verb stem has three consonants and two vowels. The final bracketed vowel is an agreement marker, hence not important to the discussion here. Now, if we compare the perfective verb stem above to its imperfective counterpart below, we find out that the latter verb stem undergoes some vocalic changes, by which the first vowel is omitted and the second vowel changes from $a$ to $u$ (the bracketed prefix $y a$ - on the imperfective verb is an agreement marker and the bracketed suffix $-u$ is an indicative marker, hence not important to the discussion here):

$$
\begin{gathered}
\text { The imperfective verb yaktubu 'write': }(y a)-k-t-u-b-(u) \\
\text { C-C-V-C }
\end{gathered}
$$

This is not the only pattern of vocalic changes to the verb stem in Standard Arabic. There are many patterns which depend on the number of consonants in the verb stem and the type of vowel in the initial and final positions.

Thus, it is clear that there is no specific morphological marker for tense in Standard Arabic, and no corresponding verbal form as well. It is argued that in this language "Tense is inferred from context or other parts of the clause" (Ryding 2005: 606). If verbs in this language can carry tense, there will be only two tenses: past and non-past. However, the imperfective verb under study shows three verbal forms: indicative, subjunctive and jussive, and it is difficult to account for these three different forms by taking them to denote three different tenses. Haywood and Nahmad (1962: 95-96) states:

Arabic, in common with other Semitic languages, is deficient in tenses, and this does not make for ease in learning. Moreover, the tenses do not have accurate timesignificances as in Indo-European languages. There are two main tenses, the Perfect al-maaDii, denoting actions completed at the time to which reference is being made; and the Imperfect al-muDaari, for incompleted actions.

\subsection{Syntactic Dependency and Case (Al-Balushi, 2011)}

Al-Balushi (2011) investigates Case assignment or checking in Standard Arabic and argues that structural Case is not licensed via agreement as has been proposed in the literature (Chomsky 2001 and subsequent work). He also argues against the assumption that Case is a tense feature [uT] on the DP as proposed by Pesetsky and Torrego (2001).

Actually, Al-Balushi revives the traditional view towards verbal forms in this language which has been advocated by Arab grammarians for a long time. This traditional view stipulates that, like nouns/DPs, verbs in Standard Arabic are assigned Case, which Al-Balushi calls Verbal Case [VC]. He assumes that the VC-assigning particles are Compelements and [VC] is valued on both $\mathrm{T}$ and $\mathrm{v}$ by a valued instance of the same feature on the head Fin, which in turn enables $\mathrm{T}$ and $\mathrm{v}$ to value the [Case] feature of the subject and object as nominative and accusative, respectively. Thus, the DP is licensed by the same feature that licenses the verb, which is [VC].

In fact, the first problem to note in Al-Balushi's analysis is the claim that verbs can have a Case, just like DPs. Under minimalist assumptions, it is argued that:

Structural Case is not a feature of the Probes (T, v), but it is assigned a value under agreement, then removed by Spell-out from the narrow syntax. The value assigned depends on the probe: nominative for $\mathrm{T}$, accusative for $\mathrm{v}$ (alternatively ergativeabsolutive, with different conditions). Case itself is not matched, but deleted under matching of $\phi$-features. (Chomsky 2001: 6.)

Actually, Al-Balushi's account of verbal morphology in Standard Arabic is a reproduction of the traditional account proposed by Arab grammarians which is based on the phonological similarity between the two markers that surface at the end of DPs as well as verbs in this language.

Moreover, Al-Balushi stipulates that while the head Fin has an unvalued [tense] feature in declarative sentences, it has only an unvalued [mood] feature in imperative, jussive and subjunctive sentences. In addition, he claims that there are two versions of the inflectional head in Standard Arabic: one with a [VC] feature, as in verbal and copular sentences, and the other without a [VC] feature, as in verbless sentences. This unusual categorization of functional heads amounts to a sheer redescription of the facts in this language, and it is clear that these stipulations are unmotivated and dubious at best.

The interesting claim made by Al-Balushi is that there are two types of finiteness: I-finiteness and C-finiteness. These two types actually correspond to two types of sentences in Standard Arabic: a) sentences which have verbs and b) 
verbless sentences. However, he links the availability of verbs in sentences to the finiteness of C/Fin. If the sentence is $\mathrm{C}$-finite, there will be a verb in the sentence; however, if, instead, the sentence is I-finite, verbs will not be licensed in this sentence. Syntactically speaking, we have an instance of a look-ahead problem. Under minimalist assumptions, the $\mathrm{v} / \mathrm{V}$ heads enter the derivation earlier than the C/Fin heads; therefore, how could C-finiteness license verbs, if verbs were not part of the lexical array in the first place?

\subsection{Syntactic Dependency and Mood (Fassi Fehri, 2012)}

Fassi Fehri (2012) investigates verbal morphology in Standard Arabic and argues that this language can be classified as a tense language rather than an aspect language, as has been documented in the literature. In his discussion of the aspect/tense categorization in Standard Arabic, he argues that "Verbal morphology exhibits two contrasting finite forms characterized by person placement (as a suffix for past, and prefix for non-past), internal vocalic changes of the verb stem, and (suffixed) mood marking in the present" (2012: 5). Thus, Fassi Fehri starts his discussion by assuming that verbs in Standard Arabic inflect for tense differently. While tense shows on the perfective verb as a suffix, it shows as a prefix on the imperfective verb. However, his idea of tense is quite unclear and most of the time tense is coupled or hyphenated with aspect. Also, if tense or aspect can be prefixed on the imperfective verb and mood is suffixed on the same verb, one wonders about agreement markers position. Again, Fassi Fehri mentions in his discussion that person feature is usually suffixed on the imperfective verb. This actually leaves number and gender features unaccounted for.

Fassi Fehri's discussion of verbal morphology takes another turn when he argues that the prefixal marker on the imperfective verb is a mood marker (2012: 77):

42) ta-y-ketb-u. 1-ebra.

ind-3-write-pl the letter

"They write the letter." or "They are writing the letter."

He contends that in the sentence above tense is expressed by a discontinuous affix, with a prefixal person feature and a suffixal number and gender features. Moreover, he argues that "The first prefix [t-] there expresses indicative (or realis) mood, as opposed to subjunctive or jussive (or more generally irrealis), marked by its absence.” (Fassi Fehri 2012: 77).

This analysis of verbal inflection on the imperfective verb seems to be messy and confusing. To start with, Fassi Fehri does not provide any syntactic account of how these verbs end up with this type of morphological markers. Second, at the beginning of his discussion he mentioned that mood is expressed as a suffix, however, he ends the discussion by postulating that prefixes can also denote mood, a dubious claim at best.

It seems that what Fassi Fehri is trying to highlight is that mood is usually expressed on the imperfective verb either as a prefix or a suffix, interchanging positions with tense/agreement markers "Mood can be introduced as distinct information from tense, which anchors the latter in a realis or irrealis world. I take the subjunctive/indicative/jussive marking as an additional mark of richness which potentially triggers movement associated with different semantic interpretations" (2012: 255).

\section{New Analysis}

I argue that the morphological markers on the three verbal forms in Standard Arabic are the manifestation of an Agree relation between $\mathrm{C} / \mathrm{T}$ and $\mathrm{v}$. I assume that the head $\mathrm{C}$ in this language has an interpretable unvalued finiteness feature [Fin] which probes an uninterpretable valued instance of the same feature on $\mathrm{v}$, assuming $\mathrm{C} / \mathrm{T}-\mathrm{v}$ feature transfer and feature sharing (Pesetsky \& Torrego 2007; Chomsky 2008). The valuation of the finiteness [Fin] feature is realized morphologically on the verb as $-u,-a$, or $-\varnothing$. The new account proposes that what has been described as 'mood markers' or 'tense markers' are actually the manifestation of an Agree relation between $\mathrm{C} / \mathrm{T}$ and $\mathrm{v}$ to value the finiteness feature [Fin]. The feature [Fin] is a formal feature that marks the syntactic dependency between $\mathrm{C} / \mathrm{T}$ and $\mathrm{v}$. This [Fin] feature is usually triggered on a Comp element, and the valuation of this feature against a valued counterpart on $\mathrm{v}$ is manifested in the three verbal forms in this language.

In fact, it has been argued that the strong syntactic dependency between $\mathrm{C} / \mathrm{T}$ and $\mathrm{v}$ can be expressed not only through the transfer and sharing of phi-features, but also finiteness features. It is argued that both phi-features and finiteness features can be spelled-out on $\mathrm{C}$ in the same manner they are spelled-out on v. For example, phi-features can be expressed on C in West Flemish (Gallego 2010: 91):

43) a. kpeinzen [CP C dan-k (ik) morgen goan ] (West Flemish)

think-1.sg that-1.sg I morgen go-1.sg

I think that I'll go tomorrow'

b. kpeinzen [CP C da-j (gie) morgen goat ] (West Flemish)

think-1.sg that-2.sg you tomorrow go-2.sg

I think that you'll go tomorrow'

Similarly, finiteness features can be spelled-out on $\mathrm{C}$ in the English examples below:

44) a. John thinks [CP C that [TP Mary T is fine ]]

b. John wants [CP C for [TP Mary T to be fine ]] 
It is to be noticed that the examples above show the syntactic dependency between the type of complementiser in $\mathrm{C}$ and the verbal form in the embedded sentence. While the complementiser that selects a finite verb, the complementiser for selects a non-finite or infinitival verbal form.

It is clear from the examples above that finiteness as a feature starts on C (cf. Rizzi 1997) and then transferred to T and shared with v. Platzack (2013: 7) argues that "The functional head C comes with an interpretable but unvalued feature for finiteness, iF. Since this feature is unvalued, it probes its c-command domain for a valued finiteness feature, $\mathrm{uF}+$ ".

\subsection{Selects Finite $T$}

There are complementisers in Standard Arabic that co-occur with the indicative form of the verb. These C-elements include the complementisers anna and inna which usually head a finite clause:

45) inna-hu yanaam-u katheeran

Comp-he $3 \mathrm{~m}$.sleep-ind a lot

'(Indeed), he sleeps a lot'

46) adhun-u anna-ha tanaam-u katheeran

1.think-ind Comp-she 3f.sleep-ind a lot

'I think that she sleeps a lot'

The finiteness nature of the above examples is manifested, in part, in the tensed verb in the embedded clause. When a clause is preceded by either of these two complementisers, the verb can surface in present or past tense:

47) inna-hu naam-a katheeran

Comp-he slept-3m a lot

'(Indeed), he slept a lot'

48) adhun-u anna-ha naam-at katheeran

1.think-ind Comp-she slept-3f a lot

'I think that she slept a lot'

This configuration is obtained when $\mathrm{C}$ transfers its features to $\mathrm{T}$ and the $\mathrm{C} / \mathrm{T}$ complex probes for the [Fin] feature. This occurs usually in finite clauses where $\mathrm{T}$ is selected by $\mathrm{C}$ and can inherit its features (Ouali 2008). This configuration occurs in simple present-tense sentences and in sentences that are headed by complementisers like anna or inna where the [Fin] feature is realized morphologically on the verb as the suffix $-u$.

\subsection{Selects Non-Finite T}

On the other hand, there are Comp-elements which co-occur with the subjunctive verbal form. These Comp-elements include an, li, kay, likay, hatta and lan. The clause that is headed by these functional elements seems to be non-finite:

49) tamann-a an tanaam-a al-fataat-u

wished-3m to 3 f.sleep-sub the-girl-nom

'He wished the girl would sleep'

50) *tamann-a an naam-at il-fataat-u

wished-3m to slept-3f the-girl-nom

'He wished the girl slept'

This configuration is obtained when the embedded $\mathrm{C}$ selects a non-finite T, i.e., when the embedded clause lacks tense. In this configuration, non-finiteness in the $\mathrm{C} / \mathrm{T}$ domain is indicated on the verb by the suffixal marker $-a$ which is licensed via Agree relation between $\mathrm{C} / \mathrm{T}$ and v. Thus, the subjunctive form of the verb is signalled by the co-occurrence of Comp-elements like an, kay and $l i$.

\subsection{T is not Selected by $C$}

The jussive verbal form is realized by a null morpheme on the verb. A viable explanation would be to assume that the head of vP is not probed by $\mathrm{C}$ in the first place, and that is why the verb surfaces without inflection for [Fin]. One could argue that the reason for this configuration is that the jussive form usually occurs in adjunction phrases, e.g., whadjuncts and conditional adjuncts which are assumed in the literature to enter the derivation post-cyclically (Chomsky 2001). It is important to note that some elements that dictate the jussive form of the verb such as lamma and the imperative marker laa are actually pure negation markers, not Comp-elements, hence the absence of any suffixal inflection on the verb in clauses that are headed by these Neg-particles. The only problem under this analysis is the case of lam which seems to be a Comp-element, though with no corresponding morphology on the verb. In this regard, I assume that lam first merges with a Neg phrase and then moves to C, along the lines proposed in Pesetsky and Torrego (2001, 2007), and hence the absence of verbal inflection with this Comp-element.

\section{On Two Types of Comp-Elements in Standard Arabic}

The important claim that I intend to emphasise here is that while the null marker on the jussive verbal form entails the absence of Agree relation between $\mathrm{C}$ and $\mathrm{v}$, the other two forms, i.e., the indicative and the subjunctive, provide information of the type of Comp-element that is heading the clause. In this regard, I argue that while the indicative form of the verb is triggered when the Comp-element selects a finite $\mathrm{T}$, the subjunctive form of the verb is manifested when the Comp-element selects a non-finite T. This amounts to saying that Standard Arabic has two types of Comp-elements: 
finite and non-finite. Ultimately, the occurrence of either type of Comp-elements is manifested on the verb through a different suffixal marker.

Alternatively, one can argue that in the case of the subjunctive verbal form, the Comp-elements heading the clause start in the derivation as T-elements and then move to C, along lines discussed in Pesetsky and Torrego (2001, 2007).

In fact, there are many properties that set these two types of Comp-elements aside. I briefly note the main differences between the two sets through comparing anna and an as representative Comp-elements of their respective type. Let's look at the examples below:

$$
\begin{array}{lll}
\text { arad-tu 1-walad-a } & \text { [an] yahdhur-a } & \text { 1-haflat-a } \\
\text { wanted-1 the-boy-acc } & \text { C } 3 \text { m.attend-sub the-party-gen }
\end{array}
$$

'I wanted the boy to attend the party.'

$$
\begin{aligned}
& \text { arad-tu [an] 1-walad-a yahdhur-a 1-haflat-a } \\
& \text { wanted-1 C the-boy-acc } 3 \text { m.attend-sub the-party-gen }
\end{aligned}
$$

'I wanted the boy to attend the party.'

The examples above show that no lexical subject may intervene between the functional particle an and the verb of the embedded clause. If an were a complementiser, there would be no problem in placing the subject after the complementiser, as in the case of the complementiser anna:

$$
\begin{aligned}
& \text { dhanant-u [anna] l-walad-a yureed-u n-nauma } \\
& \text { thought-1 C the-boy-acc 3m.want-ind the-sleep } \\
& \text { 'I thought that the boy wants to sleep.' } \\
& \text { *dhanant-u 1-walad-a [anna] yureed-u n-nauma } \\
& \text { thought-1 the-boy-acc C 3m.want-ind the-sleep } \\
& \text { 'I thought that the boy wants to sleep.' }
\end{aligned}
$$

Another characteristic of non-finite complements that are headed by the an-type Comp-elements in Standard Arabic is that such clauses can have a nominative subject:

$$
\begin{array}{lccc}
\text { tamannai-tu } & \text { [an] yajtaz-a } & \text { t-tullaab-u } & \text { 1-imtihaan-a } \\
\text { wished-1 } & \mathrm{C} & 3 \mathrm{~m} \text {.pass-sub the-students-nom the-exam-acc }
\end{array}
$$

'I wished the students would pass the exam.'

However, anna-type Comp-elements cannot have a nominative subject in the embedded clause. Instead, the subject of the embedded clause surfaces with a compulsory accusative marker:

$$
\begin{aligned}
& \text { tamannai-tu [anna] t-tullaab-a ejtaaz-u 1-imtihaan-a } \\
& \text { wished-1 C the-students-acc pass-3 the-exam-acc }
\end{aligned}
$$

'I wished that the students passed the exam.'

$$
\begin{array}{cccc}
\text { *tamannai-tu } & \text { [anna] t-tullaab-u ejtaaz-u } & \text { 1-imtihaan-a } \\
\text { wished-1 } & \mathrm{C} \text { the-students-nom pass-3 the-exam-acc }
\end{array}
$$

'I wished that the students passed the exam.'

Moreover, some an-type Comp-elements in this language can actually occur in embedded clauses that are headed by another Comp-element of the anna-type. These elements include the negative Comp-elements lam and lan:

$$
\text { tamannai-tu [anna] 1-walad-a [lam] yahdhur-a 1-haflat-a }
$$

wished-1 C the-boy-acc C 3m.attend-sub the-party-acc

'I wished that the boy didn't attend the party'

$$
\begin{aligned}
& \text { atamann-a [anna] 1-walad-a [lan] yahdhur-a 1-haflat-a } \\
& \text { wish-1 } \quad \mathrm{C} \text { the-boy-acc } \mathrm{C} \quad 3 \mathrm{~m} \text {.attend-sub the-party-acc }
\end{aligned}
$$

'I wish that the boy won't attend the party'

However, the co-occurrence of these negative Comp-elements with other Comp-elements of their same type like an or kay renders the sentence ungrammatical, as they seem to be competing for the same position or head:

$$
\begin{aligned}
& \text { *ureed-u [an] [lan] yahdhur-a 1-walad-u 1-haflat-a } \\
& \text { want-1 C C 3m.attend-sub the-boy-nom the-party-acc }
\end{aligned}
$$

'I want the boy not to attend the party'

61) *tamannai-tu [an] [lam] yahdhur-a 1-walad-u 1-haflat-a

$$
\text { wished-1 C C 3m.attend-sub the-boy-nom the-party-acc }
$$

'I wished the boy didn't attend the party' 
To negate a clause that is headed by a Comp-element of the an-type, the language has another pure negation marker laa. Compare the two examples above with the examples below:

ureed-u [an] laa yahdhur-a 1-walad-u 1-haflat-a

want-1 C Neg 3m.attend-sub the-boy-nom the-party-acc

'I want the boy not to attend the party'

$$
\text { tamannai-tu [an] laa yahdhur-a 1-walad-u 1-haflat-a }
$$

wished-1 C Neg 3m.attend-sub the-boy-nom the-party-acc

'I wished the boy didn't attend the party'

These characteristics of the an-type Comp-elements suggest that these elements or particles might have started in the derivation as T-elements, but later moved to C, along the lines discussed in Pesetsky and Torrego (2001, 2007). If this line of argumentation is on the right track, then an and the other Comp-elements in its category might have started in the derivation as T-elements heading non-finite clauses.

\section{Conclusion}

In this paper, I investigate the C/T-v syntactic dependency in Standard Arabic and the consequential effect on verbal forms in this language. The imperfective verb in this language has three different forms, dubbed the indicative, the subjunctive, and the jussive. The labels (indicative, subjunctive, jussive) are cover terms for these verbal forms and do not represent real mood. These verbal forms are indicated by three different morphological markers that surface as suffixal inflection on the verb $(-u,-a,-\varnothing)$ and co-occur with three different types of functional particles. In recent literature, there have been three main approaches to account for these morphological markers: the first approach takes them to be tense markers (Gallego 2010), the second treats them as verbal case markers (Al-Balushi 2011), and the third takes them to be mood markers (Fassi Fehri 2012). In this paper, I argue that verbal morphology in Standard Arabic is affected by functional particles residing in the $\mathrm{C} / \mathrm{T}$ domain. I argue that the morphological markers on the three verbal forms are the manifestation of an Agree relation between an interpretable unvalued finiteness feature [Fin] on C/T and an uninterpretable but valued instance of the same feature on $\mathrm{v}$, assuming feature transfer and feature sharing between C/T and v (Pesetsky \& Torrego 2007; Chomsky 2008). I also argue that the various verbal forms in Standard Arabic are mandated by the co-occurrence of three types of functional elements: C-elements, T-elements which ultimately move to $\mathrm{C}$, and imperative or negative elements.

\section{References}

Al-Balushi, R. (2011). Case in Standard Arabic: The Untraveled Paths. PhD thesis. University of Toronto.

Biberauer, T. \& Roberts, I. (2010). Subjects, Tense and Verb-Movement. In T. Biberauer, A. Holmberg, I. Roberts \& M. Sheehan (eds.), Parametric Variation: Null Subjects in Minimalist Theory, pp. 263-303. Cambridge: CUP.

Chomsky, N. (2001). Derivation by phase. In M. Kenstowicz (ed.), Ken Hale: A Life in Language, pp. 1-52. Cambridge MA: The MIT Press.

Chomsky, N. (2007). Approaching UG from below. In U. Sauerland \& H.-M. Gartner (eds.), Interfaces + Recursion = Language? Chomsky's Minimalism and the View from Syntax-semantics, pp. 1-30. Berlin: Mouton de Gruyter.

Chomsky, N. (2008). On phases. In C. Otero et al. (eds.), Foundational Issues in Linguistic Theory. Essays in Honor of Jean-Roger Vergnaud, pp. 134-166. Cambridge MA: The MIT Press.

Fassi Fehri, A. (2012). Key Features and Parameters in Arabic Grammar. Amsterdam: John Benjamins.

Gallego, A. J. (2010). Phase Theory. Amsterdam: John Benjamins.

Haywood, J. A. \& Nahmad, H. M. (1962). A New Arabic Grammar of the Written Language. Cambridge: Harvard University Press.

Ouali, H. (2008). On C-to-T $\phi$-feature transfer. In R. D’Alessandro et al. (eds.), Agreement Restrictions, pp. 159-180. Berlin: Mouton de Gruyter.

Pesetsky, D. \& Torrego, E. (2001). T-to-C movement: Causes and consequences. In M. Kenstowicz (ed.), Ken Hale: A Life in Language, pp. 355-426. Cambridge MA: The MIT Press.

Pesetsky, D. \& Torrego, E. (2007). The syntax of valuation and the interpretability of features. In S. Karimi et al. (eds.), Phrasal and Clausal Architecture. Syntactic Derivation and Interpretation, pp. 262-294. Amsterdam: John Benjamins.

Platzack, C. (2013). Head movement as a phonological operation. In Lisa Cheng \& Norbert Corver (eds.), Diagnosing Syntax, pp. 21-43. Oxford: OUP.

Rizzi, L. (1997). The fine structure of the left periphery. In L. Haegeman (ed.), Elements of grammar: Handbook in generative syntax, pp. 281-337. Dordrecht: Kluwer.

Ryding, K.C. (2005). A Reference Grammar of Modern Standard Arabic. Cambridge: Cambridge University Press. 